\title{
THE EFFECT OF ZINC BATH TEMPERATURE ON THE MORPHOLOGY, TEXTURE AND CORROSION BEHAVIOUR OF INDUSTRIALLY PRODUCED HOT-DIP GALVANIZED COATINGS
}

\author{
A. Bakhtiari*, M.R. Toroghinejad, F. Ashrafizadeh \\ Department of Materials Engineering, Isfahan University of Technology, \\ Isfahan, Iran
}

Received 13.12.2013

Accepted 18.02.2014

\begin{abstract}
The purpose of this work is to identify the influence of zinc bath temperature on the morphology, texture and corrosion behavior of hot-dip galvanized coatings. Hot-dip galvanized samples were prepared at temperature in the range of $450-480{ }^{\circ} \mathrm{C}$ in steps of $10{ }^{\circ} \mathrm{C}$, which is the conventional galvanizing temperature range in the galvanizing industries. The morphology of coatings was examined with optical microscopy and scanning electron microscopy (SEM). The composition of the coating layers was determined using energy dispersive spectroscopy (EDS) analysis. The texture of the coatings was evaluated using X-ray diffraction. Corrosion behavior was performed using salt spray cabinet test and Tafel extrapolation test. From the experimental results, it was found that increasing the zinc bath temperature affects the morphology of the galvanized coatings provoking the appearance of cracks in the coating structure. These cracks prevent formation of a compact structure. In addition, it was concluded that (00.2) basal plane texture component was weakened by increasing the zinc bath temperature and, conversely, appearance of (10.1) prism component, (20.1) high angle pyramidal component and low angle component prevailed. Besides, coatings with strong (00.2) texture component and weaker (20.1) components have better corrosion resistance than the coatings with weak (00.2) and strong (20.1) texture components. Furthermore, corrosion resistance of the galvanized coatings was decreased by increasing the zinc bath temperature.

Keywords: Galvanized morphology; Galvanized temperature; Intermetallic layers; Texture; Spangle size; Corrosion resistance; Tafel method.
\end{abstract}

\section{Introduction}

Zinc coatings are predominantly used to improve the aqueous corrosion resistance of steel by two methods, barrier protection and galvanic protection. In barrier

\footnotetext{
*Corresponding author: Amirreza Bakhtiari, bakhtiari.amirreza@gmail.com
} 
protection, the zinc coating, which separates the steel from the corrosion environment, will first corrode before the corrosive environment reaches the steel. In galvanic protection, zinc is less noble to iron at ambient conditions, and will sacrificially corrode to protect the substrate steel, even if some of the steel is exposed, as cut edges or scratches in the coating. A hot-dip galvanized coating consists of a series of layers. Starting from the steel surface, each layer is a $\mathrm{Fe}-\mathrm{Zn}$ alloy with increasingly lower iron content. These phases are: the gamma $(\Gamma)$ phase, $\mathrm{Fe}_{3} \mathrm{Zn}_{10},(23.5-28.0 \mathrm{wt} \% \mathrm{Fe})$, the gamma1 $\left(\Gamma_{1}\right)$ phase, $\mathrm{Fe}_{5} \mathrm{Zn}_{21},\left(17-19.5\right.$ wt.\% $\mathrm{Fe}$ ), the delta $(\delta)$ phase, $\mathrm{FeZn}_{10}$ and $\mathrm{FeZn}{ }_{7}$, $(7.0-11.5$ wt.\% Fe), the zeta ( $)$ phase, $\mathrm{FeZn}_{13},(5-6 \mathrm{wt} \% \mathrm{Fe})$, and the outer phase $(\eta)$ being a zinc-rich solid solution with approximately $0.003 \mathrm{wt} \% \mathrm{Fe}$ [1]. The thickness and morphology of hot-dip galvanized coatings are controlled by some factors such as, immersion time, alloying elements that added in the zinc bath and zinc bath temperature. The zinc bath temperature has an important effect on the microstructure of hot-dip galvanized coatings. Increased the zinc bath temperature, increases the dissolution rate of alloying elements in the zinc bath. This means increases the amount of alloying elements in the intermetallic phases can change the microstructure of these phases and has a great effect on the quality and the corrosion resistance of hot-dip galvanized coatings [2-4]. Verma compared the coatings formed in the temperature range of $520-550{ }^{\circ} \mathrm{C}$ with that formed at $450{ }^{\circ} \mathrm{C}$. It was found that the coating thickness reaches the maximum at $530{ }^{\circ} \mathrm{C}$ when low carbon steel $(0.042 \mathrm{wt} . \% \mathrm{C}, 0.2 \mathrm{wt} . \% \mathrm{Mn})$ was galvanized in zinc bath [5]. When the galvanizing temperature ranges from 450 to $470{ }^{\circ} \mathrm{C}$, the coating has a coherent and compact $\zeta$ layer on the top of a $\delta$ layer. $\zeta$ phase coexists with liquid zinc pocket around $480^{\circ} \mathrm{C}$. It was found that the coating thickness reaches maximum at $480{ }^{\circ} \mathrm{C}$. When the temperature is above $500{ }^{\circ} \mathrm{C}$, the coating is primarily $\delta$ phase $[6,7]$.

Crystallographic preferred orientation (texture) is an important parameter, which strongly influences the coating performances such as forming and protection duties properties. The preferred crystallographic orientation (texture) depends on external factors such as cooling rate gradient, surface condition of steel substrate during the coating solidification process and bath chemical composition $[8,9]$.

Corrosion resistance of hot-dip galvanized coatings depends on some factors such as crystallographic preferred orientation, coating thickness, roughness and zinc bath temperature $[10,11]$. In other word, corrosion resistance of hot-dip galvanized coatings strongly depends on process parameters. Verma evaluated DC electrochemical tests to identify the effect of zinc bath temperature on corrosion resistance of hot-dip galvanized coatings, the results revealed that the corrosion rate was essentially constant in the entire temperature range of $455-555{ }^{\circ} \mathrm{C}$ [12]. However, literature seems to have ignored the factor of zinc bath temperature and its effect on the texture and corrosion behavior of hot-dip galvanized coatings.

The main objective of this study is to identify the effect of the zinc bath temperature on the crystallographic preferred orientation and corrosion resistance of hot-dip galvanized coatings, the changes of the morphology of Fe- $\mathrm{Zn}$ phases at different temperature and to explain how these events effect on the corrosion resistance. 


\section{Experimental procedure}

The materials used were commercial hot-dip galvanized steel sheets. The substrate was a commercial low carbon Al-killed steel (St 14) with the composition shown by weight percent in Table 1, which corresponds to St 14 of German grade. Studied were carried out four times and the average of the results considered as the final report. In addition, production conditions such as coiling temperature, cold working percentage and annealing conditions are the same for all of the steel sheets used in this study. Production parameters of the specimens are summarized in Table 2.

Table 1 Chemical composition of steel substrate (wt.\%)

\begin{tabular}{llllllll}
\hline$C$ & $S i$ & $M n$ & $P$ & $S$ & $A l$ & $N$ & Fe \\
\hline 0.027 & 0.004 & 0.222 & 0.007 & 0.004 & 0.058 & $30 \mathrm{ppm}$ & Bal \\
\hline
\end{tabular}

Table 2 Production parameters of samples

\begin{tabular}{|c|c|c|c|c|}
\hline $\begin{array}{l}\text { Zinc bath } \\
\text { temperature } \\
\left({ }^{\circ} \mathrm{C}\right)\end{array}$ & $\begin{array}{l}\text { Sheet thickness } \\
(\mathrm{mm})\end{array}$ & $\begin{array}{l}\text { Strip-entry } \\
\text { temperature }\left({ }^{\circ} \mathrm{C}\right)\end{array}$ & $\begin{array}{l}\text { Galvanized line } \\
\text { speed }(\mathrm{m} / \mathrm{min})\end{array}$ & $\begin{array}{lr}\text { Jet } & \text { wiper } \\
\text { distance } & \text { from } \\
\text { sheet } & \text { surface } \\
(\mathrm{mm}) & \\
\end{array}$ \\
\hline 450 & 0.4 & $466 \pm 1$ & 100 & 100 \\
\hline 460 & 0.4 & $466 \pm 1$ & 100 & 100 \\
\hline 470 & 0.4 & $466 \pm 1$ & 100 & 100 \\
\hline 480 & 0.4 & $466 \pm 1$ & 100 & 100 \\
\hline
\end{tabular}

Cross sections of the coatings were studied using convectional metallography method, scanning electron microscopy (SEM) and optical microscopy. Because of high sensitivity of zinc to water, absolute alcohol was used for grinding and polishing of samples. Also, polishing was performed along the intermetallic layers and grinding was carried out employing papers (2400 or 4000). Composition of the coating layers was determined using energy dispersive spectroscopy (EDS) analysis.

The crystallographic orientation of the coatings was determined using X-ray diffraction (Philips XL Model 30, $\mathrm{Cu}$ Ka radiation, step size of $0.03 \mathrm{o}$ and counting time of $1 \mathrm{~s})$.

A $2 \theta$ scan was performed between $20 \mathrm{o}$ and $100 \mathrm{o}$ and the integrated intensities of several reflections, after background subtraction, were determined. The texture coefficients were obtained from Eq. (1).

$$
\text { Texture coefficient } \equiv \frac{\frac{I_{h k i l}}{I_{h k i l}^{o}}}{\frac{1}{n} \sum \frac{I_{h k i l}}{I_{h k i l}^{o}}}
$$

where, $I_{h k i l}$ is intensity of hkil reflection from zinc coating, $I_{h k i l}^{0}$ is intensity of hkil reflection from random sample (zinc powder) and $\mathrm{n}$ is the number of reflecting planes (10 in this study). Here, each reflection from a zinc coating of random texture would have a value equal to 1 , while a preference of grains with a particular plane parallel to the sheet surface would have a value greater than 1. Similarly, an orientation "less than random" would have a value less than 1. This technique represents 
orientations percent only from those reflections used in the calculation. It should be mentioned that in this study, summation of basal plane, high angle pyramidal planes, low angle pyramidal planes and prismatic planes has been considered and named as low angle pyramids, high angle pyramids and prisms, respectively. Some of the texture components of the zinc structure are shown in Fig.1.
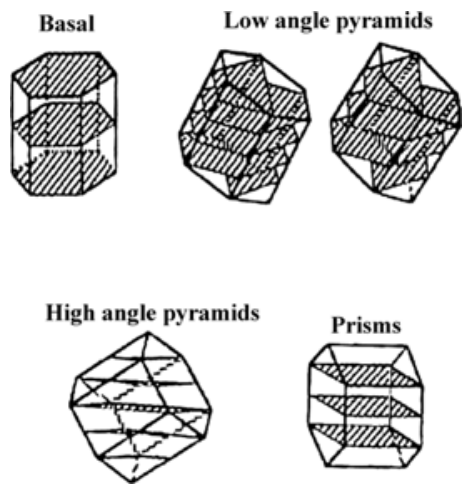

Figure 1. Schematic presentation of zinc structure texture components

After polishing, samples were quickly transferred to the test solution. Tafel polarization tests were conducted in $3.5 \% \mathrm{NaCl}$ solution at room temperature using a standard corrosion cell kit with the working electrode, two graphite center electrodes and an $\mathrm{AgCL}$ reference electrode. Potentiodynamic scanning was performed by stepping the potential at a scan rate of $1 \mathrm{mVs}-1$ from -250 to 250 .

Salt spray tests were performed under the criteria established by ASTM B117 to study the galvanized specimens.

\section{Results}

Fig. 2 shows typical cross sections of zinc coated. Four distinct coating layers of hot-dip galvanized coating can be identified in these micrographs. EDS analysis of coating layers indicated that coatings consisted of four layers: gamma, delta, zeta and eta (Table 3).

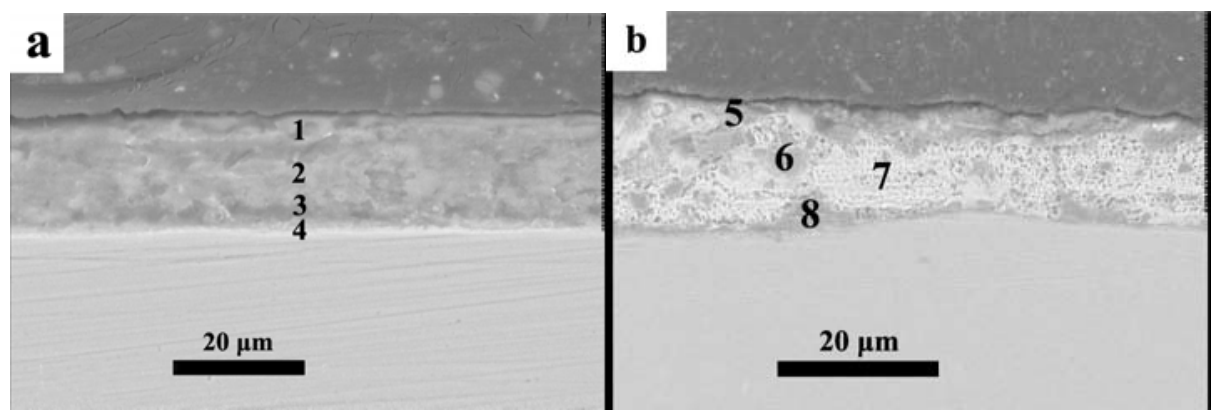




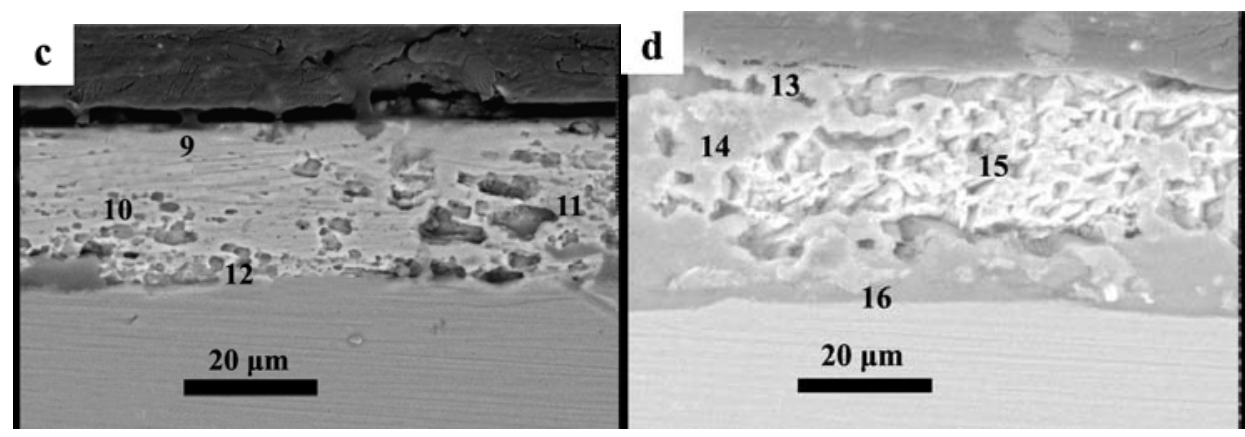

Figure 2. SEM micrographs of the coatings. (a) galvanized at $450{ }^{\circ} \mathrm{C}$, (b) galvanized at $460^{\circ} \mathrm{C}$, (c) galvanized at $470^{\circ} \mathrm{C}$ and (d) galvanized at $480{ }^{\circ} \mathrm{C}$

Table 3 Average results of the EDS microanalysis of the cross-section of the galvanized coatings

\begin{tabular}{cccc}
\hline Phase number & Zn (wt.\%) & Fe (wt.\%) & Phase \\
\hline 1 & 99.23 & 0.77 & $\eta$ \\
2 & 96.8 & 3.2 & $\zeta$ \\
3 & 91.9 & 8.1 & $\delta$ \\
4 & 82 & 18 & $\Gamma$ \\
5 & 97.3 & 2.7 & $\eta$ \\
6 & 93.5 & 6.5 & $\zeta$ \\
7 & 90.7 & 9.3 & $\delta$ \\
8 & 74.4 & 25.6 & $\Gamma$ \\
9 & 96.35 & 3.65 & $\eta$ \\
10 & 93.24 & 6.76 & $\zeta$ \\
11 & 89.5 & 10.5 & $\delta$ \\
12 & 72.14 & 27.86 & $\Gamma$ \\
13 & 96.04 & 3.98 & $\eta$ \\
14 & 91.35 & 9.65 & $\zeta$ \\
15 & 88.21 & 11.79 & $\delta$ \\
16 & 71.26 & 28.74 & $\Gamma$ \\
\hline
\end{tabular}

In this temperature range, $\left(450-480^{\circ} \mathrm{C}\right)$ zinc bath temperature has no any effect on the number of intermetallic layers. The micrographs and EDS analysis results of the coatings show that when the temperature is in the range of $450-460{ }^{\circ} \mathrm{C}$, the morphology of the coatings is relatively compact and defined $\zeta$ and $\eta$ layers on the top of a $\delta$ layer. Above $470{ }^{\circ} \mathrm{C}$, the morphology of the $\delta$ and $\zeta$ phases change significantly with the variation of zinc bath temperature. In the range of $470-480{ }^{\circ} \mathrm{C}$, compact structure changes to a fragmental structure and structure had a porous character with indefinite $\zeta$ and $\delta$ layers. The coating thickness reaches a maximum at $480{ }^{\circ} \mathrm{C}$ in the case of the same immersion time. The relationship between thickness of intermetallic layers and the zinc bath temperature is shown in Fig. 3. 


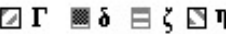

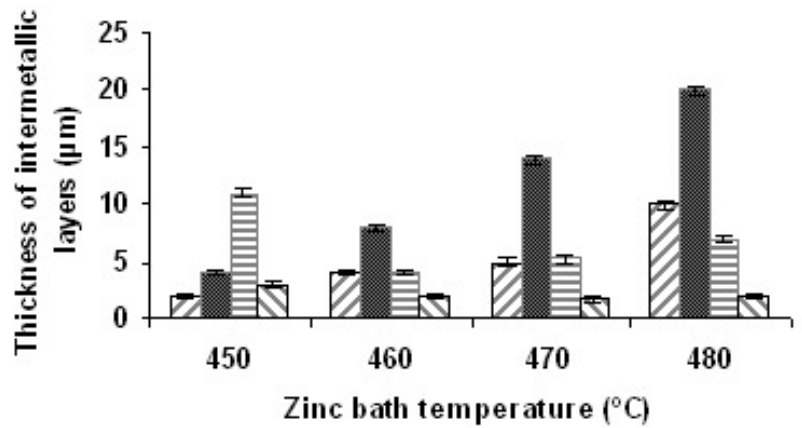

Figure 3. Relationship between zinc bath temperature and coating layers thickness

As it is seen, $\Gamma$ layer thickness increased with increasing the zinc bath temperature.

It can be seen from Fig. 4, that increasing the zinc bath temperature results in decreasing the texture coefficient of basal plane component and, conversely increasing the texture coefficients of high angles, low angles and prism components.

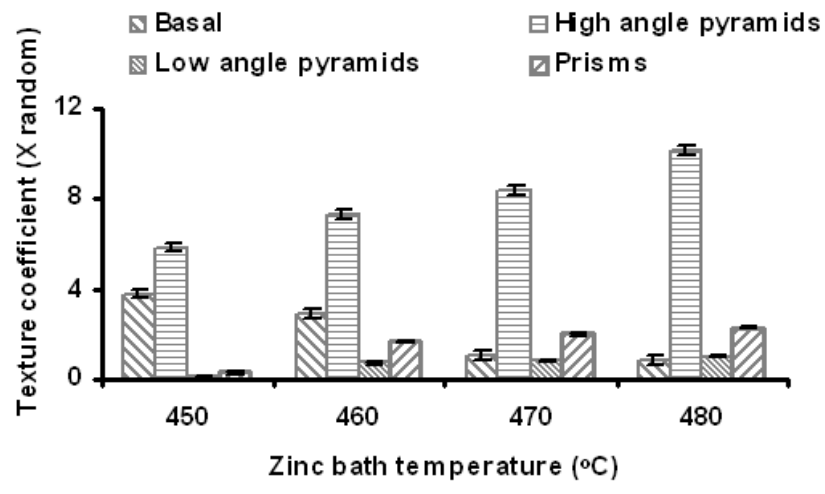

Figure 4. Effect of zinc bath temperature on texture coefficients of basal, high angle pyramids, low angle pyramids and prisms planes component of the samples

In Fig. 5, spangle sizes increase due to increasing the zinc bath temperature. It is evident that sample prepared at $450{ }^{\circ} \mathrm{C}$ has a very small spangle size and the spangle size difference between samples prepared at $450{ }^{\circ} \mathrm{C}$ and $480{ }^{\circ} \mathrm{C}$ is about $5.12 \mathrm{~mm}$. 


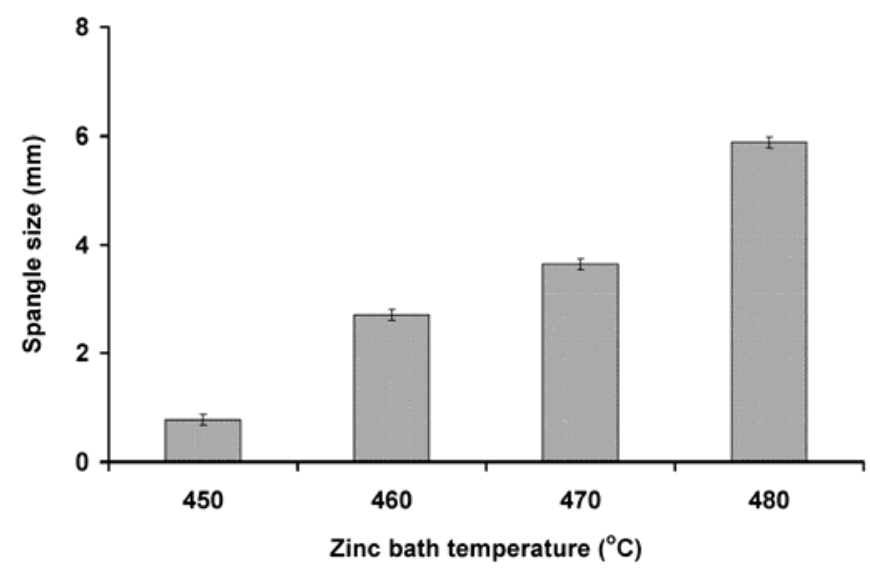

Figure 5. Effect of zinc bath temperature on spangle size

Typical polarization curves of coatings obtained in $3.5 \mathrm{wt} . \% \mathrm{NaCl}$ are shown in Fig. 6, whereas potentiodynamic polarization data are shown in Fig. 7.The result show that increasing the zinc bath temperature increases the corrosion current density. It is observed that the corrosion potential of hot-dip galvanized coatings increases with zinc bath temperature.

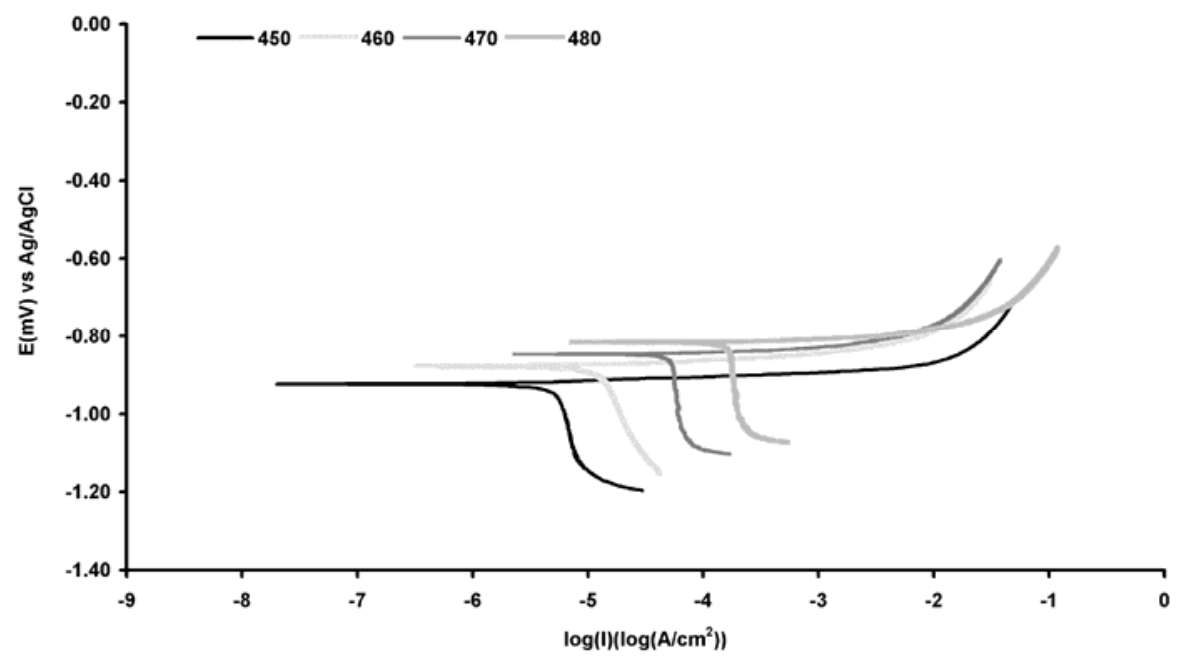

Figure 6. Potentiodynamic polarization curves of hot-dip galvanized coatings with different zinc bath temperature obtained in $3.5 \mathrm{wt} . \% \mathrm{NaCl}$ 


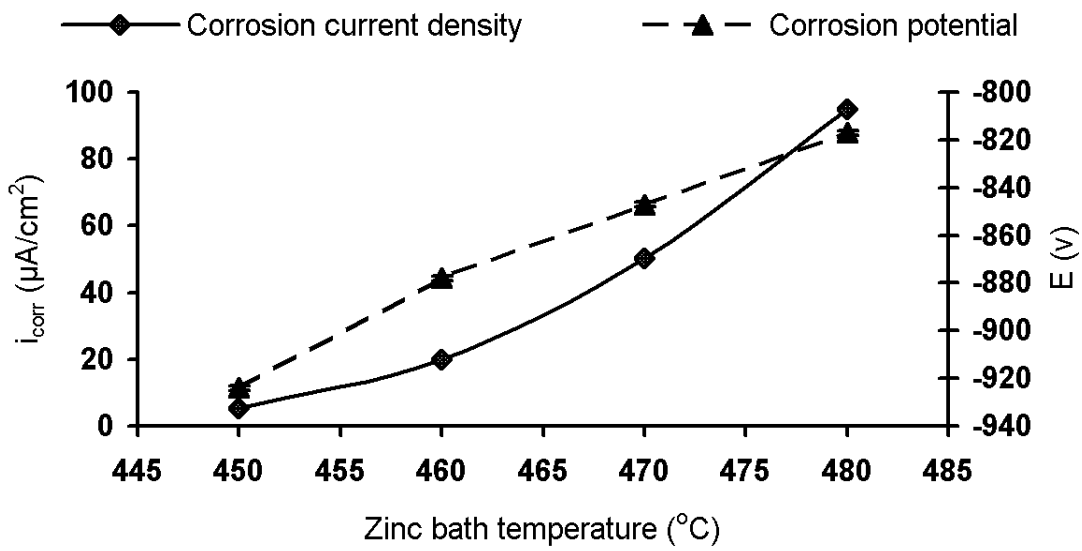

Figure 7. Electrochemical kinetic data for hot-dip galvanized coatings obtained in 3.5 $w t . \% \mathrm{NaCl}$

Fig. 8 shows that the corrosion resistance of hot-dip galvanized coatings decreases with increase in zinc bath temperature. The results were in good agreement with that of Tafel polarization test.

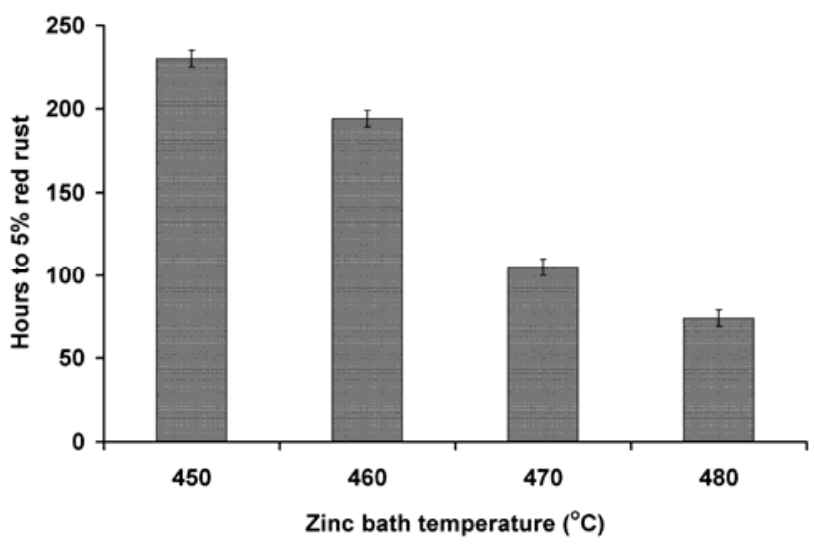

Figure 8. Relationship between zinc bath temperature and Hours to 5\% red rust

\section{Discussion}

From Fig. 2 it may be seen that coating structure changes from compact to fragmental and the porosities in $\delta$ and $\zeta$ layers become more noticeable with significantly increase of the zinc bath temperature. The segregation of the alloying elements in the boundary of the $\zeta$ phase results in the formation of the liquid paths, which prevent the formation of coherent and compact $\zeta$ layer. As a result, liquid zinc contacts the $\delta$ phase directly and erodes the $\delta$ phase $[6,7]$. Moreover, it can be concluded that the diffusing flux of dissolved iron from iron sheet into the bath is 
determined by the galvanizing temperature and increases with the temperature according to Eq. (2) [13]:

$$
D_{F e}^{Z n(L)}=2 \times 10^{-7} \exp \left(\frac{-33600}{R T}\right)\left(m^{2} s^{-1}\right)
$$

The dissolution of iron and other alloying elements increase with the increase of the diffusing flux of dissolved iron. With the increase of the temperature, the solubility of alloying elements in the $\zeta$ phase decreases, so the alloying elements will segregate at the grain boundary of the $\zeta$ phase when it forms, such as the segregation of aluminum at the galvanized coating steel interface [14]. Liquid pocket will form at the grain boundary of the $\zeta$ phase. Liquid pocket formed at the boundary of $\zeta$ phase prevents the formation of coherent and compact $\zeta$ layer which leads to the formation of liquid paths. As a result, liquid zinc can contact with the $\delta$ phase directly.

Because it is impossible to reach the equilibrium between the $\delta$ phase and liquid zinc below $4800^{\circ} \mathrm{C}[3,6,15]$, the $\delta$ phase will be eroded by liquid zinc and $\zeta$ phase will be formed according to the peritectic reaction between the $\delta$ phase and liquid zinc. Rapid interface reaction accelerates the formation of the $\zeta$ phase and makes the coating grow faster at $480^{\circ} \mathrm{C}$. The coexistence of $\zeta$ phase and liquid zinc pocket can relax the stress within the $\delta$ phase which makes the $\delta$ phase fragmental and numerous cracks will be formed within the $\delta$ phase.

It may be seen in Fig. 3 that increasing the zinc bath temperature results in increasing the thickness of $\Gamma$ layer. As it has been well demonstrated these variations would be attributed to the influence of zinc bath temperature on the diffusion rate of iron through the zinc layers, giving the chance to $\Gamma$ layer to become thicker [10].

As shown in Fig. 4, increasing the zinc bath affects the texture components. It should be noted that in hot-dip galvanized coatings, it is the texture of $\eta$ layer which is considered as the coating texture because this layer consists of about $98 \mathrm{wt} . \%$ of zinc and only about 2 wt. \% of iron. This type of texture has an important role in texture measurement of the hot-dip galvanized coatings [11]. The changes in the texture of the coatings can be attributed to an increase of the iron percentage in $\eta$ layer by increasing the zinc bath temperature. At the range from 3 to $4 \%$ of iron, the texture transforms from basal component texture to other texture components [16]. It can be assumed that increasing the amount of iron into the $\eta$ layer decreases the nucleation sites of basal planes and increases the nucleation sites of other planes. Thus, when the zinc bath temperature increased, less nuclei of basal planes form and consequently, less basal planes will be formed and these planes parallel with the surface would cover lower area of the surface.

Spangles are actually coarse zinc crystals visible by the naked eye and are formed by segregated alloying elements in cavities between segments. These spangles are harmful to the mechanical properties and corrosion resistance. The spangle size was related to the surface tension of added alloying elements. The spangle size decreases as the melt vapor surface tension of the alloying elements increases. In addition, it is proposed that spangle forms dendritically from a nucleus in the melt. Alloying elements with low interfacial energies and very limited solid solubility are highly concentrated ahead of the dendrite tip. This decreases the tip radius and increases the dendrite velocity, producing large spangles [17-18]. In addition, these elements segregate in front of the growing dendrite, lowering surface tension and allowing the growth velocity of 
the zinc dendrite to increase, resulting in larger spangles [19]. Because of minor difference between spangle sizes, it seems that the temperature of zinc bath has no strong effect on the spangle size. As above mentioned, corrosion resistance of the hotdip galvanized coatings depends on some factors; one of these factors is the structure of coatings. In the coherent and compact systems, lowest excess free energy is comparable to other systems. Increasing the temperature of zinc bath would change system to semicoherent or incoherent systems. In the incoherent systems, the total energy for break the activation free energy barrier is higher than in the coherent systems. Thus, the corrosion rate is higher in the incoherent systems than coherent systems [20].

Another important feature, which would affect the microstructure of the coatings after increasing the zinc bath temperature, is the appearance of some porosity. The porosity has an important role in corrosion phenomena and should be considered as a main cause of decreased corrosion resistance of the coatings. This high corrosion rate is of interest for some reasons. Higher surface energy in cracks influences corrosion rate and decreases corrosion resistance, together with defects such as cracks promote diffusion of corrosive environment through the coatings layers. These cracks destroy the uniformity of the coatings phases and thus the corrosive environment would easily reach to the substrate, hence the corrosion resistance decreased. In this manner, hydrogen can be produced and can be penetrate the cracks formed inside the intermetallic phases, thus reaching the steel substrate [21-22].

From Fig. 9 it is clear that the texture of coatings is directly responsible for the corrosion resistance of coatings. It is evident that (00.2) basal texture component has a key role in determining the corrosion resistance of the coatings.

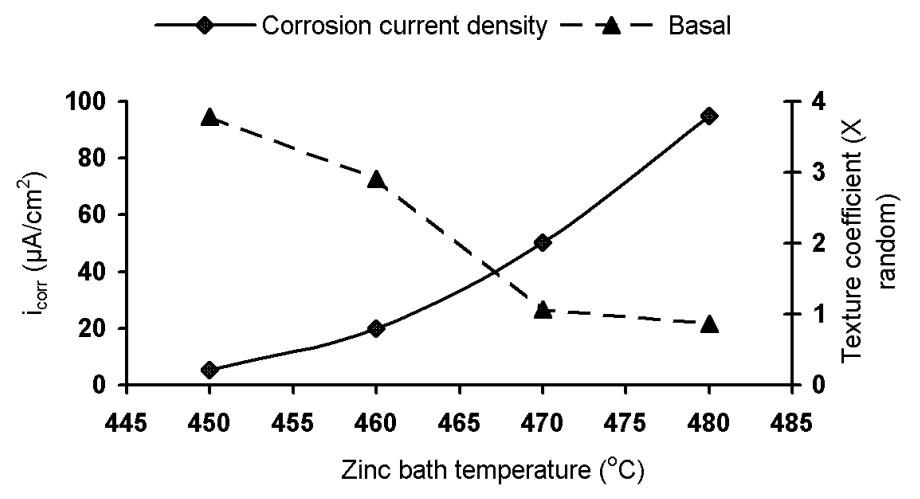

Figure 9. Relationship between zinc bath temperature, basal texture and corrosion resistance of the samples

The basal planes have the highest binding energy of the surface atoms and thus the total energy involved in the breaking of the bonds and the subsequent dissolution of atoms is highest for these planes. In the other words, surface becomes electrochemically less active because surface energy, which value is inversely proportional to the atomic spacing (d), is lowest for basal plane with respect to other planes in hep structure (for example: $1 / \mathrm{d}=0.41 ; 0.89$ and 0.85 for (00.2), (20.1) and (11.2) planes, respectively) 
[23-24]. Because of this excellent dissolution resistance, coating with higher relative intensity of (00.2) basal plane texture component will be corroded much slower than those of lower relative intensity of (00.2) basal texture component [25-26].

However, when the relative intensity of $(00.2)$ basal plane texture component decreases, it is concluded that the basal planes at the surface are substituted with other planes such as high angle pyramids or prism planes. The corrosion resistance of these planes, because of their higher surface energy and lower interatomic binding energy, is low and therefore, the coating becomes weaker against corrosion attacks [25]. As above mentioned, increasing the zinc bath temperature encourages diffusion of iron into the $\mathrm{Fe}-\mathrm{Zn}$ intermetallic layers (Fig.10) since iron is more noble than zinc, the increase of iron content in the intermetallic layers causes the increase of corrosion potential. Increasing the corrosion potential could decrease the cathodic protection ability of hotdip galvanized coatings [4].

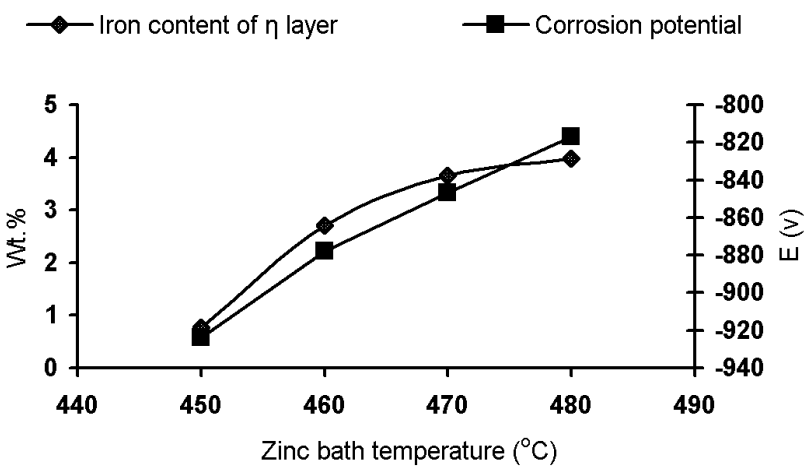

Figure 10. Relationship between zinc bath temperature, iron content of $\eta$ layer and corrosion potential of the samples

\section{Conclusions}

It is demonstrated that the texture, morphology, alloy composition and phase composition of zinc-based coatings strongly influences corrosion resistance.

1. Increase of the zinc bath temperature has the following effects:

a. prevents the formation of coherent and compact intermetallic phases,

b. increases the cracks formation in the coatings phases,

c. has no significant effect on spangle size. Spangle size is affected by the surface tension of the alloying elements,

d. results in the decrease of basal plane texture coefficient and increases the texture coefficient of high angle pyramidal, low angle pyramidal and prism planes.

2. Basal texture component has an important role in the case of corrosion resistance of hot-dip galvanized coatings. Decreased its texture intensity would decrease corrosion resistance of hot-dip galvanized coatings.

3. Corrosion resistance of the hot-dip galvanized coatings is decreased with increasing the zinc bath temperature. 
4. Corrosion potential for all the hot-dip galvanized coatings tested remained negative with respect to the steel substrate and all of the investigated coatings can provide a protection to the substrate.

5. Increasing the values of corrosion potential could decrease galvanic protection ability of hot-dip galvanized coatings.

\section{References}

[1] A. R. Marder, Prog. Mater. Sci. 45(2000) 191-271.

[2] H. Asgari, M. R. Toroghinejad, M. A. Golozar, Curr. Appl. Phys. 9 (2009) 59-66.

[3] W. Jianhua, S. Xuping, Y. Fucheng, L. Zhi, Z Manxiu, J. Alloys. Compd. 399 (2005) 214-218.

[4] F. Hanna, N. Nassif, Surf. Technnol. 21 (2002) 27-37.

[5] A. R. B. Verma, W. J Van ooij, Surf. Coat. Technol. 89 (1997) 132-142.

[6] P. Biaco, W. Jianhua, X. Su, L. Zhi, Y. Fusheng, Surf. Coat. Technol. 202 (2008) 1785-1788.

[7] P. Biaco, W. Jianhua, X. Su, L. Zhi, Y. Fusheng, Mater. Character. 60 (2009) 12761279.

[8] S. Chang, J. C. Shin, Cross. Sci. 36 (1994) 1425.

[9] M. R Toroghinejad, F. Ashrafizadeh, ISIJ. 47 (2007) 1510-1517.

[10] H. Asgari, M. R. Toroghinejad, M. A. Golozar, App. Surf. Sci. 9 (2007) $6777-$ 6769.

[11] P. R. Sere, J. D .Culcasi, C. I .Elsner, A. R .Di Salari, Surf. Coat. Technol. 122 (1999) 143-149.

[12] A. R. B. Verma, W. J Van ooij, Surf. Coat. Technol. 89 (1997) 143-150.

[13] M. L .Giorgi, P. Durighello, R. Nicolle, J. B. Guillot, J. Mater. Sci. 39 (2004) 5803-5808.

[14] A. Rodnyansky, Y. J. Warburton, L .D. Hanke, Surf. Interface Anal. 29 (2000) 215-220.

[15] S .Xuping, T. Nai-Yong, J. M .Toguri, J. Alloys. Compd. 325 (2001) 129-136.

[16] H .Park, J. A .Szpunar, Corros. Sci. 40 (1998) 525-545.

[17] F. A .Fasoyinu, F. Weinberg, Metall. Trans. 21B (1990) 549-558.

[18] G. Vourlias, N. Pistofidis, G. Stergioudis, E. Pavlidou and D .Tsipas, Phys. Stat. Solii (a). 201 (2004) 1518-1527.

[19] L .Jin-tang, W. Xin-hua, C. Chun-shan, K .Gang, C. Jin-hong, X. Qiao, Trans. Nonferrous Met. Soc. China. 17 (2007) 351-356.

[20] D.A. Porter, K.E. Easterling, Phase transformation in metals and alloys, second ed., Chapman \& Hall, New York, 1992.

[21] R.E. Reed-Hill, Physical metallurgy principles, second ed., D. Vannostrand company, New York, 1991.

[22] H Asgari, A. R .Bakhtiari, M. R. Toroghinejad, F. Ashrafizadeh, Ironmak. Steelmak. 35 (2008) 545-548.

[23] G. Reumont, J. B Vogt, A. Iost, J. Foct, Surf. Coat. Technol. 139 (2001) 265-271.

[24] H. Asgari, M. R. Toroghinejad, M. A. Golozar, J. Mater. Process. Technol. 198 (2008) 54-59.

[25] A. Bakhtiari, Metal. Mater. Eng. 18 (2012) 1-7.

[26] A. Bakhtiari, H. R. Asgari, Metal. Mater. Eng. 18 (2012) 93-101. 